\title{
Obinutuzumab Regimen
}

National Cancer Institute

\section{Source}

National Cancer Institute. Obinutuzumab Regimen. NCI Thesaurus. Code C160094.

An immunotherapy regimen consisting of obinutuzumab that may be used in the treatment of chronic lymphocytic leukemia (CLL) and small lymphocytic lymphoma (SLL). 